\title{
A Common Elements Approach to the Development of a Modular Cognitive Behavioral Theory for Chronic Loneliness
}

Anton Käll, Roz Shafran, Tomas Lindegaard, Sophie Bennett, Zafra Cooper, Anna Coughtrey and Gerhard Andersson

The self-archived postprint version of this journal article is available at Linköping University Institutional Repository (DiVA):

http://urn.kb.se/resolve?urn=urn:nbn:se:liu:diva-164198

N.B.: When citing this work, cite the original publication.

Käll, A., Shafran, R., Lindegaard, T., Bennett, S., Cooper, Z., Coughtrey, A., Andersson, G., (2020), A Common Elements Approach to the Development of a Modular Cognitive Behavioral Theory for Chronic Loneliness, Journal of Consulting and Clinical Psychology, 88(3), 269-282.

https://doi.org/10.1037/ccpoooo454

Original publication available at:

https://doi.org/10.1037/ccpo000454

Copyright: American Psychological Association

http://www.apa.org/ 
A Common Elements Approach to the Development of a Modular Cognitive Behavioural Theory for Chronic Loneliness

Anton Källa*, Roz Shafran ${ }^{\mathrm{b}}$, Tomas Nygren ${ }^{\mathrm{a}}$, Sophie Bennett ${ }^{\mathrm{b}}$, Zafra Cooper $^{\mathrm{c}, \mathrm{d}}$, Anna Coughtrey ${ }^{\mathrm{b}}$, Gerhard Andersson ${ }^{\mathrm{a}, \mathrm{e}}$

a Department of Behavioural Sciences and Learning, Linköping University, Linköping, Sweden

${ }^{\circ}$ UCL Great Ormond Street Institute of Child Health, London, England

c Department of Psychiatry, University of Oxford, England

${ }^{`}$ Department of Psychiatry, Yale University, USA

- Department of Clinical Neuroscience, Karolinska Institutet, Stockholm, Sweden

*Author for correspondence 


\begin{abstract}
Background: Loneliness is a transdiagnostic clinical phenomenon that can significantly impact mental health and wellbeing across the lifespan.
\end{abstract}

Objective: The aim was to combine existing theory and evidence-based treatment approaches to propose a comprehensive transdiagnostic cognitive behavioural analysis of the maintenance of chronic loneliness relevant across disorders, age groups and populations.

Method: A distillation and matching model-framework approach was taken to identify interventions designed to reduce loneliness. Eligible studies were coded for the presence of practice elements. The findings were combined with an analysis of the broader literature on loneliness and psychopathology to derive a comprehensive cognitive behavioural analysis of the maintenance of loneliness over time across populations.

Results: The search yielded 11 studies containing 14 practice elements with relative frequencies ranging from $7 \%$ to $64 \%$. The identified practice elements target putative mechanisms such as negative interpersonal appraisals, anxiety and social skills deficits. Counter-productive behaviour and cognitive processes such as self-focused attention were identified as maintenance factors based on the broader literature. A modular transdiagnostic model with multiple pathways is proposed to be consistent with the existing theoretical and treatment literature.

Conclusions: Combining the distillation and matching model-framework with existing theory from the literature is a novel approach for developing a model of factors that maintain loneliness over time. The model has varying treatment implications for different populations including children with autism spectrum disorders and bereaved older adults. Targeting 
transdiagnostic processes has the potential to transform interventions for loneliness across a range of formats and settings.

Keywords: loneliness, cognitive behavioural theory, intervention, practice elements

\section{What is the public health significance of this article?}

The systematic review and distillation procedure show that loneliness has been addressed with a wide range of techniques and strategies in efficacious interventions, with the most frequent ones targeting the participant's social skills. Additionally, the derived model generates potential ways of developing interventions for populations where loneliness is of concern. 


\section{Introduction}

Loneliness is a prominent social phenomenon with transdiagnostic implications for mental health (Heinrich \& Gullone, 2006). Although sometimes related to an objective lack of social contact, loneliness is considered to more closely reflect the subjective discrepancy between the actual and desired social situation (Peplau \& Perlman, 1982). Previous research suggests that a sizable proportion of the older adult population report feeling lonely often or always, with estimates ranging from $11.3 \%$ to $14.9 \%$ across a 22 -year period (Dahlberg, Agahi \& Lennartsson, 2018). In the general adult population $4.9 \%$ have reported being slightly distressed by loneliness, $3.9 \%$ moderately distressed, and $1.7 \%$ severely distressed (Beutel et al., 2017). Also, approximately $10 \%$ of children and young people often experience loneliness according to national UK survey data, with $14 \%$ of younger children aged $10-12$ and $8.6 \%$ of those aged 13-15 years reporting they 'often' felt lonely (Office for National Statistics, 2018). Data from Denmark indicate that the experience of loneliness is increasing amongst 11-15 year olds with rates of $4.4 \%$ in 1991 increasing to $7.2 \%$ in 2014 (Madsen et al., 2018).

Loneliness as a temporary, isolated phenomenon is not uncommon and often regarded as part of the everyday life experience (McWhirter, 1990; Peplau \& Perlman, 1982). Asher and Paquette (2003) have noted that such brief instances of loneliness should not be considered pathological. However, chronic loneliness is a more stable state arising from the inability of the individual to develop satisfying social relationships over time which is intrinsically aversive and associated with physical and psychiatric consequences (ShiovitzEzra \& Ayalon, 2010). The interplay between contextual and individual factors that might perpetuate this state remains to be investigated, but previous theoretical efforts have suggested that individual factors are of importance in the context of loneliness over time (e.g. Qualter et al., 2015; Cacioppo \& Hawkley, 2009). 
Loneliness can be viewed as a transdiagnostic construct that occurs in range of mental health conditions/disorders, including psychosis (Michalska da Rocha, Rhodes, Vasilopoulou \& Hutton, 2018) and suicidal behaviour (Stickley \& Koyanagi, 2016). It has also been found to be related to symptoms of generalized anxiety and depression even when adjusting for the impact of other sources of distress (Beutel et al., 2017). Additionally, loneliness has been shown to be reciprocally related to both depressive symptomology (Cacioppo, Hawkley \& Thisted, 2010; Cacioppo, Hughes, Waite, Hawkley \& Thisted, 2006) and social anxiety (Lim, Rodebaugh, Zyphur \& Gleeson, 2016), suggesting that addressing loneliness might help reduce symptoms for mental health disorders. Consistent with these data a marginal structural analysis (VanderWeele, Hawkley, Thisted and Cacioppo (2011) has shown that efforts to reduce loneliness might be a fruitful way of reducing depressive symptoms.

\section{Previous research on interventions targeting loneliness}

During the past years a number of national initiatives including those in Australia (Australian Coalition to End Loneliness, 2017) and the United Kingdom (Age UK, 2011) have focused on methods of dealing with problematic forms of loneliness. Early reviews of the literature have highlighted the possibility of using psychotherapeutic interventions (McWhirter, 1990; Rook, 1984). The focus on changing individual factors stems from the noted correlations between heightened and sustained levels of loneliness and maladaptive cognitive, perceptual, and behavioural abnormalities which has led researchers (Rook, 1984; Qualter et al., 2015) to suggest that these may be potential maintaining mechanisms that respond to cognitive and behavioural interventions.

The most thorough attempt at providing empirically-based recommendations for interventions comes from a meta-analysis conducted by Masi, Chen, Hawkley and Cacioppo (2011). The authors grouped the interventions studied on the basis of their targets. This 
resulted in four categories of intervention: those offering social support to the lonely, those offering increased social opportunities, those focused on increasing the social skills and those targeting the maladaptive cognitions regarding social situations thought to be common within this group. The last category showed the greatest average efficacy across the available studies with an effect size for decrease in loneliness of Cohen $d=0.60$. However only four randomized, controlled trials (RCTs) were included in this category and the interventions were only of moderate efficacy indicating there is a need for further well-designed research on the topic to understand maintaining mechanisms and improve outcome.

There are a number of different approaches to improving interventions (Holmes et al., 2018). Within cognitive behaviour therapy for anxiety disorders, the most successful treatment development strategy has come from (i) using clinical observation and cognitive psychology paradigms to identify the core cognitive abnormalities; (ii) constructing a theoretical account of maintenance; (iii) conducting experimental studies to test the theory; (iv) developing interventions to reverse the empirically validated maintaining factors; (v) evaluating the efficacy of the treatments in randomised controlled trials (Clark, 2004). This approach has been highly successful and further advances may be gained by continuing efforts to refine the key mechanisms of action. Implicit in Clark's approach is the potential value of evaluating the efficacy of the treatments in randomised controlled trials. Such trials can be considered as high-quality 'treatment experiments' that can inform and improve theory in an iterative manner.

One way that existing RCTs, irrespective of whether they were originally driven by theory, can be used to inform and improve theory is to synthesise their data using metaanalyses. The prior meta-analysis of interventions for loneliness (Masi et al., 2011) and further studies published since the last systematic investigation of individual-level interventions (e.g. Cohen-Mansfield et al., 2018; Theeke et al., 2016) suggest the potential 
utility of traditional CBT-techniques such as cognitive restructuring. A recent pilot study has also provided preliminary evidence of the feasibility of disseminating a manualised CBT treatment via the internet for this population (Käll et al., in press). However, the application of the meta-analytical approach to the field of loneliness interventions has limitations since it involves attempting to synthesise highly heterogeneous studies that target different populations affected by loneliness. For example, it is likely that a different approach will be needed for bereaved older adults with established social networks and a young person with autism who may lack the ability to read social cues. Another complementary approach that is particularly well suited to developing transdiagnostic, modular interventions that match the variety of different manifestations of the problems and needs of individuals to the treatment technique is the 'Common Elements' approach of Chorpita, Daleiden and Weisz (2005). This approach involves the development of a distillation and matching model-framework (DMM) where elements of different interventions and treatment manuals can be distilled into profiles and then matched to potentially moderating factors such as the age group or ethnicity of the participants. The level of analysis thus shifts from the overall treatment protocol to its elements, picking out specific components that characterise successful interventions (i.e. interventions that perform significantly better than a control group on a given parameter). It is certainly the case that just because an overall intervention package has been found to be effective, it does not mean that all of its specific elements are effective as well. Since it is not possible to evaluate all the specific elements across all interventions, identifying the common elements across effective interventions is another way of approaching the question of which specific elements may actually be effective in treatment.

The process of distillation and matching includes five steps; reviewing the area of interest; creating a data set to include in the analysis; coding the discrete components, referred to as practice elements; selecting a data-reduction algorithm which is subsequently 
mined to allow for practice element profiles to be generated and interpretation by a domain expert to cross-reference the generated pattern against theory. The method has been applied to aggregate treatment elements of evidence-based manualized treatments of psychiatric disorders among children and adolescents (Chorpita \& Daleiden, 2009) and distil profiles for engagement practices in children's mental health services (Becker, Boustani, Gellatly \& Chorpita, 2018; Becker et al., 2015). It has not previously been applied to the adult population, or to the problem of loneliness. A further advantage of this approach is that it lends itself to being integrated with the existing theoretical literature to facilitate the development of a modular cognitive behavioural theory of the maintenance of loneliness. Not only can these theoretical and clinical data-synthesis approaches be integrated, but knowledge of efficacious interventions and intervention components may also directly inform the development of theory which can generate further treatment hypotheses to be tested in an iterative manner.

This study had two novel aims. First, to apply the distillation of practice elements to examine which elements characterize successful psychological interventions targeting loneliness and to see whether these differed across demographic (e.g. age, gender) or clinical variables (e.g. the presence of disabilities or neuropsychiatric disorders). Second, to combine the identified practice elements together with the existing literature to propose a testable, modular cognitive-behavioural theory of chronic loneliness.

First Aim: to use the distillation and matching procedure to examine practice elements that characterize successful psychological interventions targeting loneliness

\section{Method}

Identifying studies to include 
Published peer-reviewed articles evaluating individual-level interventions targeting loneliness were identified using the search string (TITLE-ABS-KEY (lonel*) AND TITLE-ABSKEY ( treat*) OR TITLE-ABS-KEY ( interv*) ) on Scopus and ((Lonel* AND) Interven* OR Treat*)) AND SU Lonel* on PsycINFO yielding 4337 and 711 results, respectively. There were no age or date restrictions, but only manuscripts written in English were included. Additionally, a meta-analysis of loneliness interventions (Masi et al., 2011) was consulted to identify potential studies not found with the search strings. Because a candidate article previously known by a member of the coding team was not found with use of the aforementioned databases, an additional search was conducted using ERIC with ((Lonel* AND) Interven* OR Treat*)) AND SU Lonel* as a search string. This yielded 43 additional papers. After scanning through abstracts, candidate articles containing the relevant characteristics (i.e. an individual-level intervention with loneliness as specified outcome measure) were screened to see whether they fit the criteria for inclusion (see Figure 1 for a PRISMA diagram of the flow of information through the phases of the identification of papers for inclusion). Articles were included into the coding process on the basis of: (a) Containing a standardized intervention seeking to change the participant's behavioural and cognitive responses and/or coping strategies with the intention of reducing loneliness. Interventions focusing on strictly altering environmental aspects for participants were excluded (e.g. animal support-therapy or providing social support through a volunteer programme); (b) Being shown to compare favourably to a control condition in a randomized study (i.e. a significant difference in loneliness post-intervention as compared to the control group); (c) Using a quantitative scale to measure loneliness as a primary outcome. In the case of there being several primary outcome measures or an aggregate primary outcome (e.g. psychosocial functioning such as in the case of Gantman, Kapp, Orenski \& Laugeson, 2012) loneliness had to be explicitly mentioned among the primary outcome measures. Where there were more 
than one treatment conditions with potential differences in regard to their practice elements all conditions were coded provided that they compared favourably to a control condition. Each winning condition (i.e. a condition that performs significantly better than a control group on the loneliness measure) is referred to as a study group.

\section{Coding}

The coding of practice elements was conducted by two licensed clinical psychologists and doctoral students under the supervision of the senior author. Authors for the included studies were contacted to obtain a manual, a detailed protocol of the intervention, and/or a clarification of the elements of the intervention if the information was not available. The order of priority for inferring what elements an intervention contained was: (a) from the manual; (b) from a research protocol with details on the intervention (e.g. Theeke \& Mallow, 2015); (c) the published article itself. The taxonomy of the elements was, when available, based on previous definitions found in studies describing and detailing the DMM-procedure (e.g. Chorpita et al., 2005). An initial list of 12 plausible practice elements was created as a base for the coding process. The list was created to represent possible practice elements based on the previous literature on loneliness and related clinical problems and diagnoses. However, as the coding progressed, four additional candidate elements not on the initial list emerged. The final list of practice elements used for coding was thus the result of an iterative process involving both the coders and the senior investigator with all being involved in the final consensus judgment in what constituted distinct practice elements. When the list was finalized after a first round of coding all studies were re-coded in accordance with the final version of the practice element list. Discrepancies during the coding were discussed in meetings involving both of the coders along with the senior author. In the case of disagreement, the senior investigator made the final decision. The elements and their definitions along with inter-rater reliability for the initial coding can be found in Table 1. 
Table 1 here

Analysis

The initial plan to conduct both a distillation and matching procedure was revised on account of the low number of eligible articles which would have rendered the use of data-mining algorithms unreliable and underpowered. The choice was made to distil the elements of the included articles and generate a relative count of the practice elements found.

\section{Results}

Studies identified for inclusion

A total of 11 articles with 14 eligible study groups met the inclusion criteria and were included for coding. Study characteristics can be seen in Table 2.

Table 2 here

\section{Practice elements}

Figure 2 shows the relative frequencies of practice elements across all winning study groups. The presence/absence of practice elements within each study group is presented in Table 3 . The most common practice element found $(n=10)$ within the study groups were social skills and communication training, present in $64 \%$ of the studies. As can be seen in Figure 1 this was followed by mapping social opportunities and role-playing, present in seven (50\%), psychoeducation in six (43\%), stress management and emotional awareness in five (36\%) and cognitive in four (29\%). Two (14\%) of the study groups included at least one of the problem solving, mindfulness, relaxation, and/or reviewing relationship experiences elements. The presence of elements related to mindfulness and emotional awareness would seem to be legitimate alternatives to an appraisal-based approach to addressing the emotional distress associated with loneliness. Three of the practice elements, identifying personal strengths, life review, and goal-setting were each present in a single study group, equivalent to a relative frequency of $7 \%$. When creating the practice elements scheme, it was anticipated that activity 
scheduling and exposure would be common practice elements due to the prominence of low mood, anxiety and avoidance in clinical presentations of loneliness and the established efficacy of these elements to address such difficulties (Nathan \& Gorman, 2015). However, activity scheduling and exposure were not present in any of the study groups. There were no clear distinctions between the practice elements used for different populations, ages or settings.

Figure 2 here

Table 3 here

Second aim: Combining the identified practice elements together with the broader literature to produce a testable, modular cognitive-behavioural analysis of chronic loneliness.

It has been argued above that important information about maintaining mechanisms can be gained from 'treatment experiments' such as RCTs. However, when the number of studies is limited, using such experiments in isolation to develop theories of the maintenance of psychopathology runs the risk of missing variables not included in the existing interventions that may nevertheless perpetuate psychopathology. This is especially relevant in an area where the interventions up to this point have been largely atheoretical. The broader literature as well as clinical observation and other empirical approaches may offer further promising candidate variables that may contribute to the maintenance of a particular disorder, or in this case, loneliness. For example, the longitudinal study of Vanhalst et al., (2015) found that sensitivity to rejection and lack of positive responding to social inclusion predicted chronic loneliness. Theoretical efforts to understand the development and maintenance of loneliness include Cacioppo and Hawkley's (2009) model based in social neuroscience and focusing on attention and cognition in those experiencing loneliness and the reaffiliation motive described by Qualter et al., (2015). 
This broader literature on loneliness considers many of the practice elements identified within the DMM, including social skills and opportunity, emotional skills and cognitive strategies. However, one key factor identified within the broader literature on loneliness (Cacioppo et al., 2015; Cacioppo \& Hawkley, 2009; Qualter et al., 2015; Vanhalst et al., 2015) but not present as a practice element within the systematic distillation is behavioural avoidance. Although not found in RCTs of loneliness interventions, behavioural strategies that address avoidance of social situations have been used successfully in nonstandardized RCTs (Hopps, Pepin \& Boisvert, 2003), and non-randomized trials (Bouwman, Aartsen, van Tilburg \& Stevens, 2017). It has also been linked to loneliness in observational studies (Nurmi, Toivonen, Salmela \& Eronen, 1997; Watson \& Nesdale, 2012).

Research considering avoidance in chronic loneliness to date suggests that it may take one of two forms, the first based on outright avoidance of situations containing the prospect of rejection. For example, Watson and Nesdale (2012) found that young adults may withdraw from social contact to avoid possible rejection. Such avoidance leads to the person being deprived of positive contrary information that they will in fact not be rejected, thereby perpetuating further avoidance. Another form of avoidance involves increased use of social media/'parasocial relationships', which may be positively reinforcing in the short-term and potentially beneficial in some ways (Yang, 2016), but ultimately such behaviour can also be counter-productive and may prevent more reinforcing social relationships in-person (Baek, Bae \& Jang, 2013; Pittman \& Reich, 2016). Nowland, Necka and Cacioppo (2018) have noted there would seem to exist a particular risk among the chronically lonely to use social media and related strategies in a way that interferes with the possibility of achieving satisfying longterm connections with others. Using social media in a goal-directed fashion as a means to reach out and create opportunities for valued social contact would be a potentially fruitful 
strategy to reduce loneliness, while accessing social media channels as a distraction or substitute for contact with others is proposed to be a risk for chronic loneliness.

Avoidance of social contact is also key within theoretical and treatment models of social anxiety (Clark \& Wells, 1995; Clark et al., 2006). These models have additionally suggested that self-focused attention is a key mechanism in the maintenance of social anxiety and is particularly associated with maintenance of avoidance behaviours. Within the social anxiety model, attention is shifted to detailed monitoring and observation of a person's own internal bodily state and cognitions about this state, rather than externally oriented to the other people in the room. This again leads to a person being deprived of realistic information (e.g. that other people do not perceive them in the same way that they perceive themselves) and therefore in part to avoidance of further social situations. Similarly, self-focused attention has been suggested to be related to the maintenance of loneliness in both observational (Lee \& Ko, 2018) and experimental research (Jones, Hobbs \& Hockenbury, 1982). People may perceive their interactions with others in a particular way even if this is not objectively how others perceive them; this type of self-focused attention may be associated with those who subjectively feel lonely even when objectively they are not socially isolated. Given these findings in the literature we suggest that any comprehensive theoretical account of the maintenance of chronic loneliness needs to consider avoidance and self-focused attention despite the fact that none of these factors were identified in the distilled practice elements.

Our proposed model of maintenance for chronic loneliness can be seen in Figure 3. Like other cognitive behavioural approaches, it (a) focuses on maintenance mechanisms with a view to reversing those mechanisms to alleviate loneliness and b) allows for testing of clinically relevant mechanisms of change for this population. The model was designed to be transdiagnostic and modular since some individuals such as those with neurodevelopmental disabilities such as autism spectrum disorder are particularly prone to social skills deficits 
(American Psychiatric Association, 2013) and this will be their 'starting point' into the maintenance cycle. Others, such as older adults who have been bereaved, may have their loneliness maintained primarily by the discrepancy between their actual and desired situation, which is then perpetuated by maladaptive cognitive and behavioural tendencies such as interpersonal appraisals of rejection and avoidance. Even within this group, it has been suggested that there is a need for interventions to be individually tailored (Victor et al., 2018). Those with clinical or sub-clinical levels of social anxiety would require an intervention targeting their self-focused attention and avoidance (Clark \& Wells, 1995; Hoffman \& Otto, 2017). Individuals' personal challenges such as mental or physical health issues may be significant maintenance factors that need to be taken into consideration. The model also clearly links chronic variations of loneliness to the common, transient state but by focusing on the maintaining mechanisms allows for development of hypotheses as to why some people continue to feel lonely over time while others do not. Table 4 provides an extended description of the components in the model, their rationale for inclusion and relationship with other putative maintaining factors in the broader literature.

In summary, the Common Elements identified from the DMM were combined to form a model of the maintenance of loneliness based on existing cognitive behavioural models of anxiety disorders, particularly social anxiety (Clark \& Wells, 1995) and the broader literature on theories of the maintenance of loneliness (e.g., Cacioppo \& Hawkley, 2009; Qualter et al., 2015).

Figure 3 here.

Table 4 here.

\section{Discussion}

The development of theory and practice within the field of psychotherapy need not be considered mutually exclusive processes. The present study is the first to combine the 
theoretical literature with a systematic investigation of the discrete elements that make up successful interventions aimed at reducing loneliness to produce a testable cognitivebehavioural model of loneliness.

After the distillation procedure 14 discrete practice elements were found across 11 eligible studies. The focus on elements, rather than the interventions as a whole, is valuable given the sparse amount of published research on the topic and creates the possibility of devising new interventions incorporating previously successful elements. The distillation focused on identifying the practice elements of interventions that targeted individual factors. It was found that there is a large degree of heterogeneity between interventions within this category. Only one practice element was present in a majority of the study groups, while eight were coded two or fewer times. Of even greater interest than the relative frequency of elements however, is a consideration of the possible means whereby a change in loneliness is achieved in these trials. The results from the present distillation lends some credibility to claims that CBT strategies and techniques may be particularly efficacious in dealing with loneliness. A proportion of the studies reported using CBT either as the treatment format (McWhirter \& Horan, 1996; Williams et al., 2004) or as a theoretical base for the intervention (Cohen-Mansfield et al., 2018; Theeke et al., 2016), but study designs were not adequate for determining the extent to which the efficacy of interventions was due to specific treatment elements.

After consideration of the relevant theoretical and broader cognitive-behavioural literature alongside clinical observations, it was concluded that self-focused attention, avoidance and counter-productive behaviour such as having 'parasocial' relationships were also putative important processes in the maintenance of chronic loneliness. These processes needed to be integrated with the constructs derived from the practice elements approach in order to produce a comprehensive theory of the maintenance of chronic loneliness. The 
interventions (or practice elements in this context) for these additional putative maintaining processes are also cognitive behavioural in nature and include exposure, behavioural experiments and behavioural activation (e.g. Hofmann \& Smits, 2008; Schrieber et al., 2015; Soucy Chartier \& Provencher, 2013). Although it was unexpected that these processes were not represented at all within the distillation, it should be noted that the strength of CBT is often thought to be its ability to apply general behavioural and cognitive theories, findings, and processes in a way that promotes long-term well-being without relying on any one specific intervention or technique (e.g. Waltman \& Sokol, 2017). We considered it desirable to add these processes to enable the production of a comprehensive explanatory model that could be applied in different clinical presentations in a modular fashion, as opposed to an over-inclusive 'one-size fits all' approach.

Combining the broader literature on loneliness and associated mental health disorders with the treatment literature on loneliness helps patch together a scattered and incomplete field of research and generate new avenues of investigation for future studies, including highlighting shared underlying processes such as negative interpersonal appraisals and avoidance. Future research on the topic will reveal whether the generated hypotheses hold up to the scrutiny of empirical testing, particularly with regard to the broader applicability of the model across the different age range, mental health disorders and populations. The number of studies available for review and the overlap, or lack thereof, in practice elements included preclude conclusions regarding what works for whom, under what circumstances, in what format. Future work should focus on these important questions in order to facilitate the personalised use of the modular approach. As an illustrative example of the need for personalisation and how the model could be applied in clinical practice, it is anticipated that the starting point of an intervention for a young adult with autism spectrum disorder and chronic loneliness would be a social skills intervention to increase valued social contacts (e.g., 
Gantman et al., 2012); the intervention would subsequently need to address the discrepancy between actual and desired social contacts and to 'update' negative appraisals that others will be rejecting that may have been true prior to the social skills intervention. Neither addressing beliefs nor addressing social skills in isolation is likely to be sufficient to address loneliness according to the model. For an older adult with lifelong social anxiety, the focus of the intervention is likely to lie within addressing cognitive processes within the social domain. For bereaved older adults experiencing chronic loneliness in the absence of a mental health disorder, the intervention may not be psychological and the model is likely to be less applicable but other interventions to reduce social isolation such as providing opportunities for social contact may be more appropriate. The proposed model should not exist in isolation to the established, social and societal-based interventions to address loneliness (e.g., Haslam, Cruwys, Haslam, Dingle \& Chang, 2016; Wang et al., 2017) or those developed for specific subgroups such as those with psychosis (see Lim, Gleeson, Alvarez-Jimenez \& Penn, 2018; Michalska da Rocha et al., 2018) or older adults (see Gardiner et al., 2018). Rather, the current model can be seen as partially explaining some of the internal barriers to accessing socially prescribed interventions. The interpersonal and intrapersonal approaches are complementary and should be used together.

Our hope is that the present study serves to further the process of developing successful intervention for reducing loneliness and associated mental health disorders. The proposed model of maintenance generates further hypothesis to be tested in a truly iterative way - developing treatments informed by theory, treatment experiments and clinical experience. The inherent modularity of the proposed theoretical framework is partially in response to the heterogeneity within the existing interventions which ranges from focusing on changing the participants' stance towards the experience of loneliness found in the study by Creswell et al. (2012) to focusing on increasing the participant's social skills in interventions 
from the PEERS programme (Gantman et al., 2012; Matthews et al., 2018). The modularity is also necessary given the heterogeneity of the clinical populations affected and changes that occur across the lifespan (Victor, 2018). For example, loneliness has been described as relatively common within populations with physical disabilities (Russell, 2009) and chronic conditions (Maes et al., 2017), both of which may provide an additional obstacle to the successful altering of social networks in accordance with a client's abilities. A unifying theoretical framework may also facilitate inquiries into potential mediators and moderators of change and provide a starting point for addressing the question of what works for whom in the context of loneliness.

Certain limitations need to be considered. As with all methods for data synthesis, the quality of the product is inherently reliant on the data from which it is derived. The most important limitation with regard to the DMM procedure was the lack of studies that at minimum compared the intervention to be studied against a control group and randomized participants to groups. This made it impossible to match practice element profiles to specific subgroups. With the small number of studies that met the inclusion criteria it is hardly surprising that the counts for some of the practice elements were found to be low. Previous applications of the DMM-framework (Becker et al., 2015; Chorpita \& Daleiden, 2009) have noted similar issues with substantially larger samples and have tried to remedy this by not including practice elements with low counts to help reduce the impact of base rate extremes on the inter-rater reliability. The inter-rater reliability for the initial coding procedure was generally very good, with kappas ranging from strong to perfect for 11 of the 15 practice elements (McHugh, 2012) but psychoeducation and problem solving had a lower-than-ideal kappa that might be considered problematic, especially as the former element was found to be relatively prevalent among the study groups. Another limitation of the present approach is that the inclusion of all winning study groups, rather than just one group from each study, has the 
potential to (i) inflate the relative frequency of elements, especially in studies with as small a sample as in the present case and (ii) does not consider the magnitude of difference between the treatment and the control condition. The impact of specific practice elements across different ratings of frequency of loneliness remains unknown and is something that warrants attention in future studies. Four studies were excluded as loneliness was not the primary outcome variable and other studies were excluded due to lack of randomization. Broadening the eligibility criteria may have identified further studies and practice elements and processes that could potentially be of use, for example the non-randomised 'Groups4Health' intervention focusing on social identity (Haslam et al., 2016) or interventions explicitly incorporating emotion regulation strategies. Finally, manuals were not available for all studies, something that might have made inferences about the presence/absence of practice elements less reliable.

There were also limitations associated with the process used to identify the broader literature of relevance to loneliness. A systematic review of the loneliness literature and associated mental health problems was not conducted but instead the authors used their clinical knowledge of related cognitive behavioural interventions for anxiety and depression, as well as their knowledge of the theoretical literature on loneliness. The recent systematic review of Mann and colleagues (2017) was consistent with the current study in that it was concluded the most promising interventions related to 'changing cognitions'. However, how the proposed, intrapersonal approach, relates to broader interpersonal and societal interventions for loneliness remains to be established.

An additional limitation is that the distillation procedure did not take the overall efficacy of the interventions into account. All elements within and between studies were treated as equally efficacious and responsible for the observed reductions of loneliness. The reasoning behind not weighing the elements in relation to the overall efficacy of the 
interventions was twofold; first of all, not all studies used the same measure of loneliness. While the UCLA Loneliness Scale was used in a majority of the interventions as the outcome measure, other measures (including the Social and Emotional Loneliness Scale for Adults; DiTommaso \& Spinner, 1993) were used as well. Given the lack of literature on similarities and differences in psychometric properties for these questionnaires it was not deemed feasible to treat them as equivalent when measuring change in loneliness. Secondly, the populations included in the studies were heterogeneous not only in demographic characteristics and sample size, but also in terms of their reported levels of loneliness. Some studies (e.g. Theeke, 2016) used a cut-off, while some studies included participants regardless of whether they had expressed concerns regarding loneliness. While a focus on loneliness was required for a study to be included in the DMM-procedure, this heterogeneity might result in biased estimates of the efficacy of certain elements.

Overall, although the lack of well-designed trials aimed at reducing loneliness is concerning, the study adds important knowledge regarding the building blocks of cognitive and behavioural interventions targeting chronic loneliness. While previous attempts at systematizing the knowledge from published trials (e.g. Masi et al., 2011) have provided an initial indication of the efficacy for these kinds of interventions, our distillation and subsequent theoretical model supplements the available literature with information at a different level of analysis and leads to further opportunities for treatment development. We suggest that the proposed modular theory of the maintenance of loneliness is regarded only as a starting point for extensive and independent testing and development. We hope that it stimulates further work particularly in terms of new transdiagnostic interventions that can be applied to different populations and settings that are fully integrated with interpersonal innovations in the field. 


\section{Acknowledgements}

All research at Great Ormond Street Hospital NHS Foundation Trust and UCL Great Ormond Street Institute of Child Health is made possible by the NIHR Great Ormond Street Hospital Biomedical Research Centre. The views expressed are those of the author(s) and not necessarily those of the NHS, the NIHR or the Department of Health. 


\section{References}

* Denotes article included in the distillation procedure

Age UK. (2011). Safeguarding the convoy: a call to action from the Campaign to End Loneliness. Abingdon, Age UK Oxfordshire. Retrieved from https://www.campaigntoendloneliness.org/wp-content/uploads/Safeguarding-the$\underline{\text { Convoy.-A-call-to-action-from-the-Campaign-to-End-Loneliness.pdf }}$

American Psychiatric Association (2013). Diagnostic and statistical manual of mental disorders. (5th ed.). Washington, DC: American Psychiatric Publishing Asher, S. R., \& Paquette, J. A. (2003). Loneliness and peer relations in childhood. Current Directions in Psychological Science, 12(3), 75-78. doi:10.1111/1467-8721.01233

Australian Coalition to End Loneliness. (2017). Australian Coalition to End Loneliness. Retrieved from https://www.endloneliness.com.au/

Beck, A. T. (1979). Cognitive therapy and the emotional disorders. Penguin.

Baek, Y. M., Bae, Y., \& Jang, H. (2013). Social and parasocial relationships on social network sites and their differential relationships with users' psychological well-being. Cyberpsychology, Behavior And Social Networking, 16(7), 512-517. doi:10.1089/cyber.2012.0510

Becker, K. D., Boustani, M., Gellatly, R., \& Chorpita, B. F. (2018). Forty years of engagement research in children's mental health services: Multidimensional measurement and practice elements. Journal of Clinical Child \& Adolescent Psychology, 47(1), 1-23. doi:10.1080/15374416.2017.1326121

Becker, K. D., Brandt, N. E., Lee, B. R., Lindsey, M., Daleiden, E. L., \& Chorpita, B. F. (2015). The common elements of engagement in children's mental health services: Which elements for which outcomes? Journal of Clinical Child and Adolescent Psychology, 44(1), 30-43. doi:10.1080/15374416.2013.814543 
Beutel, M. E., Klein, E. M., Brähler, E., Reiner, I., Jünger, C., Michal, M., . . Tibubos, A. N. (2017). Loneliness in the general population: prevalence, determinants and relations to mental health. BMC Psychiatry, 17, 1-7. doi:10.1186/s12888-017-1262-x

Bouwman, T. E., Aartsen, M. J., van Tilburg, T. G., \& Stevens, N. L. (2017). Does stimulating various coping strategies alleviate loneliness? Results from an online friendship enrichment program. Journal of Social and Personal Relationships, 34, 793-811. doi:10.1177/0265407516659158

Cacioppo, J. T., \& Hawkley, L. C. (2009). Perceived social isolation and cognition. Trends in Cognitive Sciences, 13(10), 447-454. doi:10.1016/j.tics.2009.06.005

Cacioppo, J. T., Hawkley, L. C., \& Thisted, R. A. (2010). Perceived social isolation makes me sad: 5-year cross-lagged analyses of loneliness and depressive symptomatology in the Chicago Health, Aging, and Social Relations Study. Psychology and Aging, 25(2), 453-463. doi:10.1037/a0017216

Cacioppo, J. T., Hughes, M. E., Waite, L. J., Hawkley, L. C., \& Thisted, R. A. (2006). Loneliness as a specific risk factor for depressive symptoms: cross-sectional and longitudinal analyses. Psychology and Aging, 21(1), 140-151. doi:10.1037/08827974.21.1.140

*Chiang, K.-J., Chu, H., Chang, H.-J., Chung, M.-H., Chen, C.-H., Chiou, H.-Y., \& Chou, K.R. (2010). The effects of reminiscence therapy on psychological well-being, depression, and loneliness among the institutionalized aged. International Journal of Geriatric Psychiatry, 25(4), 380-388. doi:10.1002/gps.2350

Chorpita, B. F., \& Daleiden, E. L. (2009). Mapping evidence-based treatments for children and adolescents: Application of the distillation and matching model to 615 treatments from 322 randomized trials. Journal of Consulting and Clinical Psychology, 77(3), 566-579. doi:10.1037/a0014565 
Chorpita, B. F., Daleiden, E. L., \& Weisz, J. R. (2005). Identifying and selecting the common elements of evidence based interventions: A distillation and matching model. Mental Health Services Research, 7(1), 5-20. doi:10.1007/s11020-005-1962-6

Clark, D. M. (2004). Developing new treatments: on the interplay between theories, experimental science and clinical innovation. Behaviour Research and Therapy, 42(9), 1089-1104. doi:10.1016/j.brat.2004.05.002

Clark, D. M., Ehlers, A., Hackmann, A., McManus, F., Fennell, M., Grey, N., . . . Wild, J. (2006). Cognitive therapy versus exposure and applied relaxation in social phobia: A randomized controlled trial. Journal of Consulting and Clinical Psychology, 74(3), 568-578. doi:10.1037/0022-006X.74.3.568

Clark, D. M., \& Wells, A. (1995). A cognitive model of social phobia. In Heimberg, R. G., Liebowitz, M. R., Hope, D. A., \& Schneier, F. R. (Eds.), Social phobia: Diagnosis, assessment, and treatment. (pp. 69-93). New York, NY: Guilford Press.

*Cohen-Mansfield, J., Hazan, H., Lerman, Y., Shalom, V., Birkenfeld, S., \& Cohen, R. (2018). Efficacy of the I-SOCIAL intervention for loneliness in old age: Lessons from a randomized controlled trial. Journal of Psychiatric Research, 99, 69-75. doi:10.1016/j.jpsychires.2018.01.014

Cohen-Mansfield, J., \& Parpura-Gill, A. (2007). Loneliness in older persons: A theoretical model and empirical findings. International Psychogeriatrics, 19(2), 279-294. doi:10.1017/S1041610206004200

*Creswell, J. D., Irwin, M. R., Burklund, L. J., Lieberman, M. D., Arevalo, J. M. G., Ma, J., . . . Cole, S. W. (2012). Mindfulness-Based Stress Reduction training reduces loneliness and pro-inflammatory gene expression in older adults: A small randomized controlled trial. Brain, Behavior and, Immunity, 26(7), 1095-1101. doi:10.1016/j.bbi.2012.07.006 
Dahlberg, L., Agahi, N., \& Lennartsson, C. (2018). Lonelier than ever? Loneliness of older people over two decades. Archives of Gerontology and Geriatrics, 75, 96-103. doi:10.1016/j.archger.2017.11.004

DiTommaso, E., \& Spinner, B. (1993). The development and initial validation of the Social and Emotional Loneliness Scale for Adults (SELSA). Personality and Individual Differences, 14(1), 127-134. doi:10.1016/0191-8869(93)90182-3

*Frankel, F., Myatt, R., Sugar, C., Whitham, C., Gorospe, C. M., \& Laugeson, E. (2010). A Randomized controlled study of parent-assisted children's friendship training with children having autism spectrum disorders. Journal of Autism and Developmental Disorders, 40(7), 827-842. doi:10.1007/s10803-009-0932-z

*Gantman, A., Kapp, S. K., Orenski, K., \& Laugeson, E. A. (2012). Social Skills Training for young adults with high-functioning autism spectrum disorders: A randomized controlled pilot study. Journal of Autism and Developmental Disorders, 42(6), 10941103. doi:10.1007/s10803-011-1350-6

Gardiner, C., Geldenhuys, G., \& Gott, M. (2018). Interventions to reduce social isolation and loneliness among older people: an integrative review. Health \& Social Care in the Community, 26(2), 147-157. doi:10.1111/hsc.12367

Haslam, C., Cruwys, T., Haslam, S. A., Dingle, G., \& Chang, M. X.-L. (2016). Groups 4 Health: Evidence that a social-identity intervention that builds and strengthens social group membership improves mental health. Journal of Affective Disorders, 194, 188195. doi:10.1016/j.jad.2016.01.010

Heinrich, L. M., \& Gullone, E. (2006). The clinical significance of loneliness: A literature review. Clinical Psychology Review, 26(6), 695-718. doi:10.1016/j.cpr.2006.04.002 
Hofmann, S. G., \& Otto, M. W. (2017). Cognitive behavioral therapy for social anxiety disorder: Evidence-based and disorder specific treatment techniques. New York: Routledge.

Hofmann, S. G., \& Smits, J. A. J. (2008). Cognitive-behavioral therapy for adult anxiety disorders: A meta-analysis of randomized placebo-controlled trials. The Journal of Clinical Psychiatry, 69(4), 621-632. doi:10.4088/JCP.v69n0415

Holmes, E. A., Ghaderi, A., Harmer, C. J., Ramchandani, P. G., Cuijpers, P., Morrison, A. P., ... Craske, M. G. (2018). The Lancet Psychiatry Commission: The Lancet Psychiatry Commission on psychological treatments research in tomorrow's science. The Lancet Psychiatry, 5(3), 237-286. doi:10.1016/S2215-0366(17)30513-8

Hopps, S. L., Pépin, M., \& Boisvert, J.-M. (2003). The effectiveness of cognitive-behavioral group therapy for loneliness via inter relaychat among people with physical disabilities. Psychotherapy: Theory, Research, Practice, Training, 40(1-2), 136-147. doi:10.1037/0033-3204.40.1-2.136

Jones, W. H., Hobbs, S. A., \& Hockenbury, D. (1982). Loneliness and social skill deficits. Journal of Personality and Social Psychology, 42(4), 682-689. doi:10.1037/00223514.42.4.682

Käll, A., Jägholm, S., Hesser, H., Tiger Norkvist, B., Mathaldi, A., Andersson, F., . . . Andersson, G. (in press). Internet-administered cognitive-behavioral therapy against loneliness - a randomized controlled pilot trial. Behavior Therapy.

Leary, M. R. (1990). Responses to social exclusion: Social anxiety, jealousy, loneliness, depression, and low self-esteem. Journal of Social and Clinical Psychology, 9(2), 221229. doi:10.1521/jscp.1990.9.2.221 
Lee, Y., \& Ko, Y.-g. (2018). Feeling lonely when not socially isolated: Social isolation moderates the association between loneliness and daily social interaction. Journal of Social \& Personal Relationships, 35(10), 1340-1355. doi:10.1177/0265407517712902

Lim, M. H., Gleeson, J. F. M., Alvarez-Jimenez, M., \& Penn, D. L. (2018). Loneliness in psychosis: a systematic review. Social Psychiatry and Psychiatric Epidemiology, 53(3), 221-238. doi:10.1007/s00127-018-1482-5

Lim, M. H., Rodebaugh, T. L., Zyphur, M. J., \& Gleeson, J. F. M. (2016). Loneliness over time: The crucial role of social anxiety. Journal of Abnormal Psychology, 125(5), 620630. doi: $10.1037 / \mathrm{abn} 0000162$

Long, C. R., Seburn, M., Averill, J. R., \& More, T. A. (2003). Solitude experiences: Varieties, settings, and individual differences. Personality and Social Psychology Bulletin, 29(5), 578-583. doi:10.1177/0146167203029005003

Madsen, K. R., Holstein, B. E., Damsgaard, M. T., Rayce, S. B., Jespersen, L. N., \& Due, P. (2018). Trends in social inequality in loneliness among adolescents 19912014. Journal of Public Health, fdy133. doi:10.1093/pubmed/fdy133

Maes, M., Van den Noortgate, W., Fustolo-Gunnink, S. F., Rassart, J., Luyckx, K., \& Goossens, L. (2017). Loneliness in children and adolescents with chronic physical conditions: A meta-analysis. Journal of Pediatric Psychology, 42(6), 622-635. doi:10.1093/jpepsy/jsx046

Mann, F., Bone, J. K., Lloyd-Evans, B., Frerichs, J., Pinfold, V., Ma, R., ... \& Johnson, S. (2017). A life less lonely: the state of the art in interventions to reduce loneliness in people with mental health problems. Social Psychiatry and Psychiatric Epidemiology, 52(6), 627-638. doi:10.1007/s00127-017-1392-y 
Masi, C. M., Chen, H.-Y., Hawkley, L. C., \& Cacioppo, J. T. (2011). A meta-analysis of interventions to reduce loneliness. Personality and Social Psychology Review, 15(3), 219-266. doi:10.1177/1088868310377394

*Matthews, N. L., Orr, B. C., Warriner, K., DeCarlo, M., Sorensen, M., Laflin, J., \& Smith, C. J. (2018). Exploring the effectiveness of a peer-mediated model of the PEERS curriculum: A pilot randomized control trial. Journal of Autism and Developmental Disorders, 48(7), 2458-2475. doi:10.1007/s10803-018-3531-z

McHugh, M. L. (2012). Interrater reliability: the kappa statistic. Biochemia Medica, 22(3), 276-282.

McWhirter, B. T. (1990). Loneliness: A review of current literature, with implications for counseling and research. Journal of Counseling \& Development, 68(4), 417-422. doi: 10.1002/j.1556-6676.1990.tb02521.x

*McWhirter, B. T., \& Horan, J. J. (1996). Construct validity of cognitive-behavioral treatments for intimate and social loneliness. Current Psychology, 15(1), 42-52. doi10.1007/BF02686933

Meulders, A., Van Daele, T., Volders, S., \& Vlaeyen, J. W. S. (2016). The use of safetyseeking behavior in exposure-based treatments for fear and anxiety: Benefit or burden? A meta-analytic review. Clinical Psychology Review, 45, 144-156. doi: 10.1016/j.cpr.2016.02.002

Michalska da Rocha, B., Rhodes, S., Vasilopoulou, E., \& Hutton, P. (2018). Loneliness in psychosis: A meta-analytical review. Schizophrenia Bulletin, 44(1), 114-125. doi:10.1093/schbul/sbx036

Mörtberg, E., Hoffart, A., Boecking, B., \& Clark, D. M. (2015). Shifting the focus of one's attention mediates improvement in cognitive therapy for social anxiety disorder. 
Behavioural and Cognitive Psychotherapy, 43(1), 63-73.

doi:10.1017/S1352465813000738

Nathan, P.E., \& Gorman, J.M. (2015) (Eds). A guide to treatments that work. Oxford University Press. Fourth Edition.

Nowland, R., Necka, E. A., \& Cacioppo, J. T. (2018). Loneliness and social internet use: Pathways to reconnection in a digital world? Perspectives on Psychological Science, 13(1), 70-87. doi: 10.1177/1745691617713052

Nurmi, J. E., Toivonen, S., Salmela-Aro, K., \& Eronen, S. (1997). Social strategies and loneliness. The Journal Of Social Psychology, 137(6), 764-777. doi:10.1080/00224549709595497

Office for National Statistics (2018). Children's and young people's experiences of loneliness: 2018. Retrieved from https://www.ons.gov.uk/peoplepopulationandcommunity/wellbeing/articles/childrensa ndyoungpeoplesexperiencesofloneliness/2018

Peplau, L. A., \& Perlman, D. (1982). Loneliness: a sourcebook of current theory, research and therapy. New York: Wiley.

Pittman, M., \& Reich, B. (2016). Social media and loneliness: Why an Instagram picture may be worth more than a thousand Twitter words. Computers in Human Behavior, 62, 155-167. doi:10.1016/j.chb.2016.03.084

Qualter, P., Vanhalst, J., Harris, R., Van Roekel, E., Lodder, G., Bangee, M., .. . Verhagen, M. (2015). Loneliness across the life span. Perspectives on Psychological Science, 10(2), 250-264. doi:10.1177/1745691615568999

Rook, K. S. (1984). Promoting social bonding: Strategies for helping the lonely and socially isolated. American Psychologist, 39(12), 1389-1407. doi:10.1037/0003066X.39.12.1389 
Russell, D. (2009). Living arrangements, social integration, and loneliness in later life: The case of physical disability. Journal of Health and Social Behavior, 50(4), 460-475. doi:10.1177/002214650905000406

*Samarel, N., Tulman, L., \& Fawcett, J. (2002). Effects of two types of social support and education on adaptation to early-stage breast cancer. Research in Nursing \& Health, 25(6), 459-470. doi: 10.1002/nur.10061

Schreiber, F., Heimlich, C., Schweitzer, C., \& Stangier, U. (2015). Cognitive therapy for social anxiety disorder: The impact of the "self-focused attention and safety behaviours experiment" on the course of treatment. Behavioural and Cognitive Psychotherapy, 43(2), 158-166. doi:10.1017/S1352465813000672

Shiovitz-Ezra, S., \& Ayalon, L. (2010). Situational versus chronic loneliness as risk factors for all-cause mortality. International Psychogeriatrics, 22(3), 455-462. doi:10.1017/S1041610209991426

Soucy Chartier, I., \& Provencher, M. D. (2013). Behavioural activation for depression: Efficacy, effectiveness and dissemination. Journal of Affective Disorders, 145(3), 292299. doi: $10.1016 /$ j.jad.2012.07.023

Spithoven, A. W. M., Bijttebier, P., \& Goossens, L. (2017). It is all in their mind: A review on information processing bias in lonely individuals. Clinical Psychology Review, 58, $97-$ 114. doi:10.1016/j.cpr.2017.10.003

Stickley, A., \& Koyanagi, A. (2016). Loneliness, common mental disorders and suicidal behavior: Findings from a general population survey. Journal of Affective Disorders, 197, 81-87. doi:10.1016/j.jad.2016.02.054

*Theeke, L., A., Mallow, J., A., Moore, J., McBurney, A., Rellick, S., \& VanGilder, R. (2016). Effectiveness of LISTEN on loneliness, neuroimmunological stress response, psychosocial functioning, quality of life, and physical health measures of chronic 
illness. International Journal of Nursing Sciences, 3(3), 242-251.

doi:10.1016/j.ijnss.2016.08.004

Theeke, L. A., \& Mallow, J. A. (2015). The development of LISTEN: A novel intervention for loneliness. Open Journal of Nursing, 5(2), 136-143. doi:10.4236/ojn.2015.52016

Treanor, M., \& Barry, T. J. (2017). Treatment of avoidance behavior as an adjunct to exposure therapy: Insights from modern learning theory. Behaviour Research and Therapy, 96, 30-36. doi: 10.1016/j.brat.2017.04.009

VanderWeele, T. J., Hawkley, L. C., Thisted, R. A., \& Cacioppo, J. T. (2011). A marginal structural model analysis for loneliness: Implications for intervention trials and clinical practice. Journal of Consulting and Clinical Psychology, 79(2), 225-235. doi:10.1037/a0022610

Vanhalst, J., Luyckx, K., Soenens, B., Van Petegem, S., Weeks, M. S., \& Asher, S. R. (2015). Why do the lonely stay lonely? Chronically lonely adolescents' attributions and emotions in situations of social inclusion and exclusion. Journal of Personality and Social Psychology, 109(5), 932-948. doi:10.1037/pspp0000051

Vanhalst, J., Luyckx, K., Van Petegem, S., \& Soenens, B. (2018). The detrimental effects of adolescents' chronic loneliness on motivation and emotion regulation in social situations. Journal of Youth and Adolescence, 47(1), 162-176. doi:10.1007/s10964017-0686-4

Victor, C., Mansfield, L., Kay, T., Daykin, N., Lane, J., Grigsby-Duffy, L., Tomlinson, A., \& Meads, C. (2018). An overview of reviews: the effectiveness of interventions to address loneliness at all stages of the life-course. What Works Centre for Wellbeing. Retrieved from https://whatworkswellbeing.org/wp/wp- 
content/uploads/woocommerce uploads/2018/10/Full-report-Tackling-loneliness-Oct-

\section{8.pdf}

Watson, J., \& Nesdale, D. (2012). Rejection sensitivity, social withdrawal, and loneliness in young adults. Journal of Applied Social Psychology, 42(8), 1984-2005. doi:10.1111/j.1559-1816.2012.00927.x

Waltman, S. H., \& Sokol, L. (2017). Chapter 1 - The generic model of cognitive behavioral therapy: A case conceptualization-driven approach. In Hofmann, S. G., \& Asmundson, G. J. G., (Eds.), The Science of Cognitive Behavioral Therapy (pp. 3-17). San Diego: Academic Press.

Wells, A., Clark, D. M., Salkovskis, P., Ludgate, J., Hackmann, A., \& Gelder, M. (1995). Social phobia: The role of in-situation safety behaviors in maintaining anxiety and negative beliefs. Behavior Therapy, 26(1), 153-161. doi:10.1016/S00057894(05)80088-7

*Williams, A., Hagerty, B. M., Yousha, S. M., Horrocks, J., Hoyle, K. S., \& Liu, D. (2004). Psychosocial effects of the Boot Strap intervention in navy recruits. Military Medicine, 169(10), 814-820. doi:10.7205/milmed.169.10.814

Yang, C. (2016). Instagram use, loneliness, and social comparison orientation: Interact and browse on social media, but don't compare. Cyberpsychology, Behavior, and Social Networking, 19(12), 703-708. doi: 10.1089/cyber.2016.0201

Young, J. E. (1982). Loneliness, depression and cognitive therapy: Theory and application. In Peplau L. A., \& Perlman D. (Eds.). Loneliness: A sourcebook of current theory, research and therapy (pp. 379-406). New York: Wiley.

*Zhang, N., Fan, F.-m., Huang, S.-y., \& Rodriguez, M. A. (2018). Mindfulness training for loneliness among Chinese college students: A pilot randomized controlled trial. International Journal of Psychology, 53(5), 373-378. doi: 10.1002/ijop.12394 
Figure 1: PRISMA diagram to show process of identification of articles included in

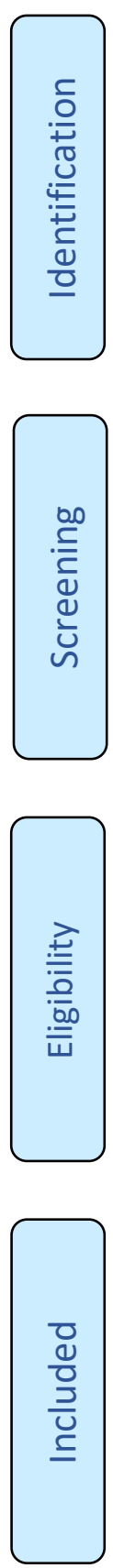

distillation procedure

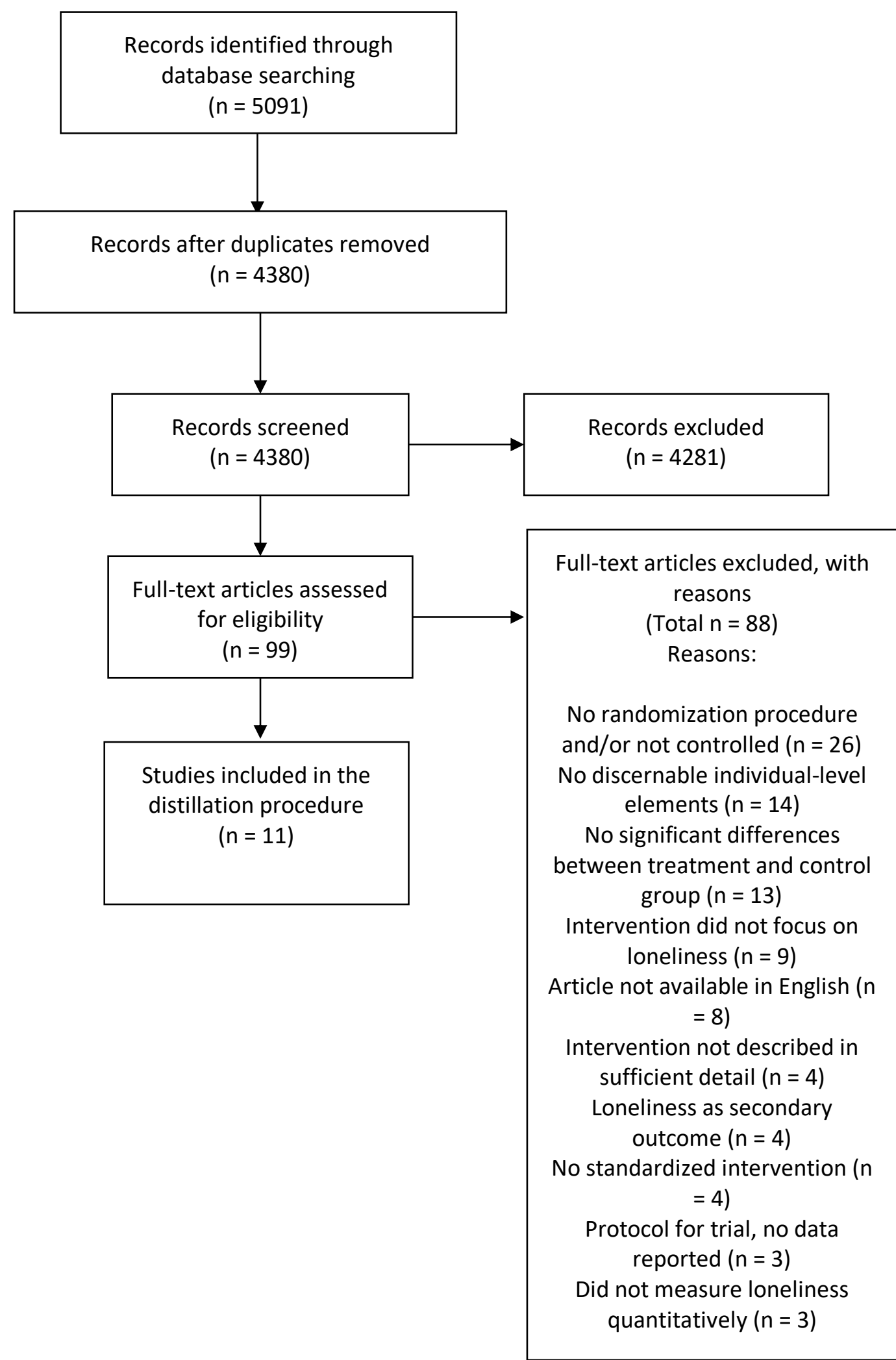




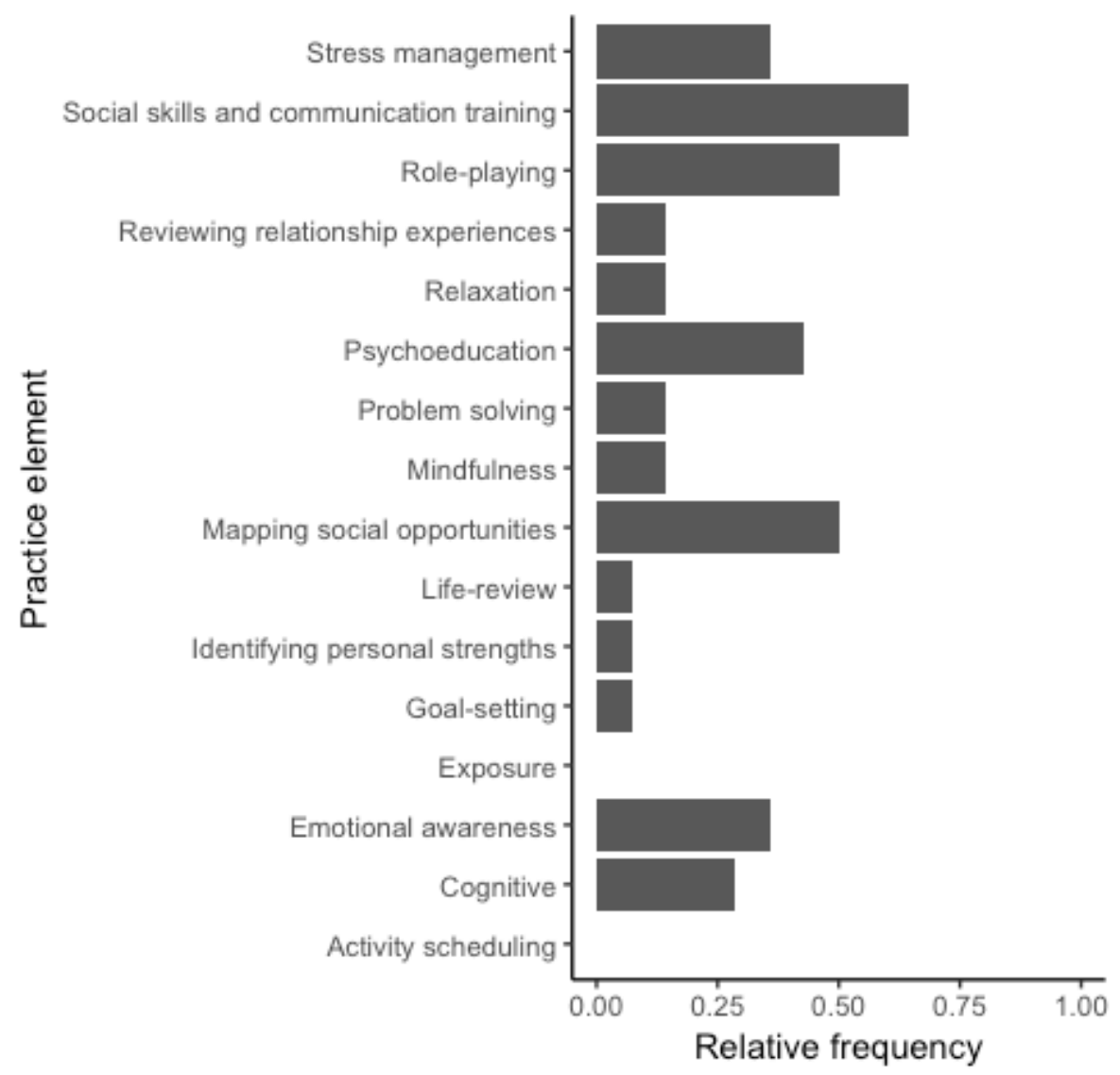

Figure 2. Relative frequency of the practice elements found in eligible studies 


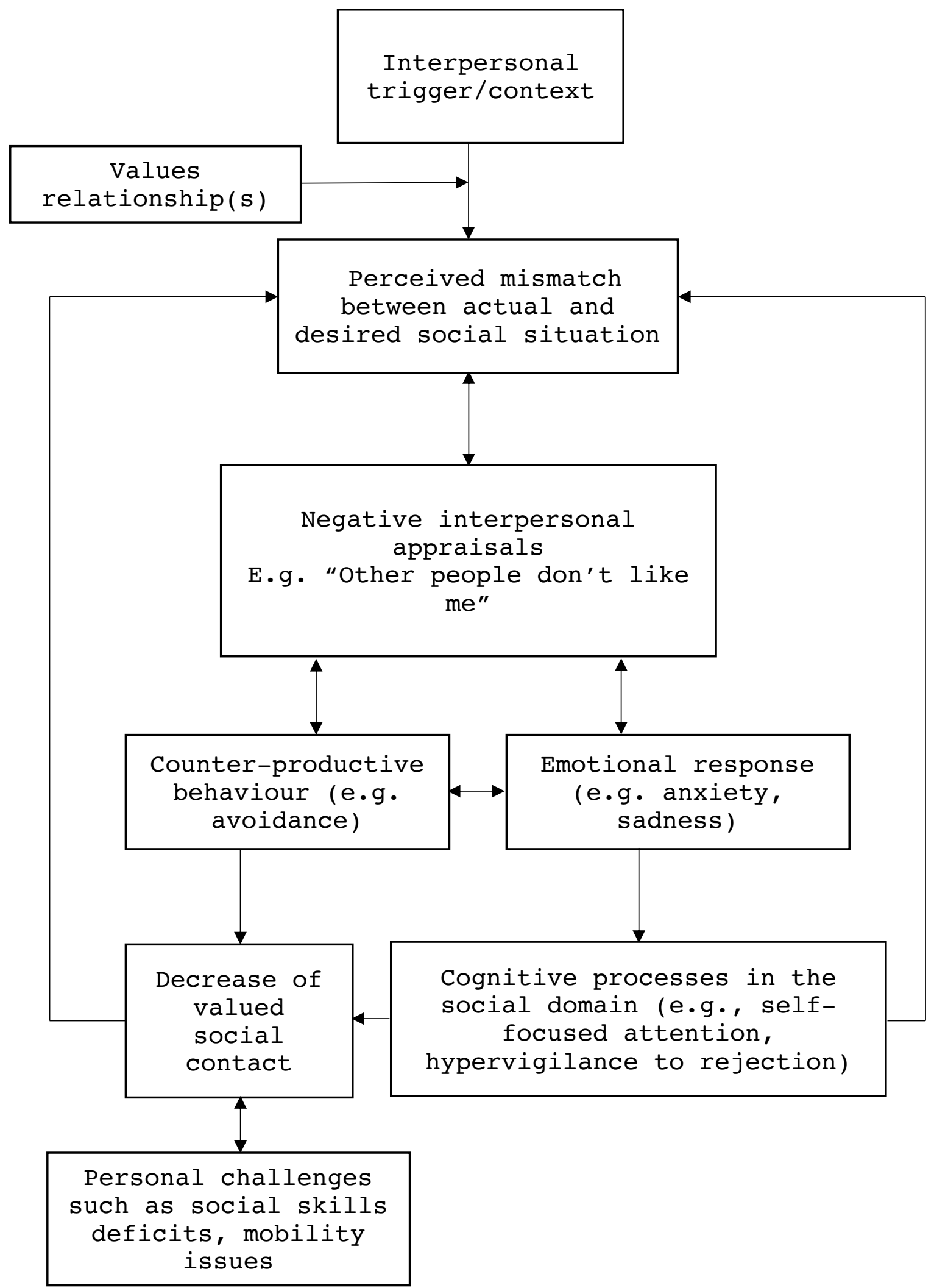

Figure 3. A cognitive behavioural analysis of the maintenance of chronic loneliness. 
Table 1. Practice elements found in the interventions, their definition, and inter-rater reliability for the initial coding

\begin{tabular}{|c|c|c|}
\hline Element & Definition & $\begin{array}{l}\text { Inter-rater } \\
\text { reliability } \\
\text { (к) }\end{array}$ \\
\hline Cognitive & $\begin{array}{l}\text { Any techniques designed to alter interpretation of events through } \\
\text { examination of the participant's reported thoughts, typically through the } \\
\text { generation and rehearsal of alternative counter-statements. This can } \\
\text { sometimes be accompanied by exercises designed to comparatively test } \\
\text { the validity of the original thoughts and the alternative thoughts through } \\
\text { the gathering or review of relevant information. }\end{array}$ & 0.84 \\
\hline Problem solving & $\begin{array}{l}\text { Techniques, discussions, or activities designed to bring about solutions to } \\
\text { targeted problems, usually with the intention of imparting a skill for how } \\
\text { to approach and solve future problems in a similar manner. }\end{array}$ & 0.59 \\
\hline Mindfulness & $\begin{array}{l}\text { Techniques or practices designed to allow the retaining of a non- } \\
\text { judgmental, observational stance to internal and external experiences. }\end{array}$ & 1 \\
\hline Exposure & $\begin{array}{l}\text { Techniques designed to let the participant gradually approach a feared } \\
\text { stimulus in an attempt to reduce avoidance and adverse reactions related to } \\
\text { said stimulus long-term. }\end{array}$ & 1 \\
\hline Relaxation & $\begin{array}{l}\text { Techniques or practices designed to reduce activity in the sympathetic } \\
\text { nervous system, thus reducing the bodily sensations related to such } \\
\text { activity. }\end{array}$ & 1 \\
\hline $\begin{array}{l}\text { Social skills and } \\
\text { communication } \\
\text { training }\end{array}$ & $\begin{array}{l}\text { Discussions, techniques, or activities designed to enhance a participant's } \\
\text { ability to accomplish goal-directed interpersonal tasks. }\end{array}$ & 1 \\
\hline Psychoeducation & $\begin{array}{l}\text { Discussions, lectures, or written materials aimed at providing information } \\
\text { about a psychological problem, diagnosis, or phenomenon. Often contains } \\
\text { information about hypothesized mechanisms of maintenance and potential } \\
\text { solutions. }\end{array}$ & 0.42 \\
\hline Role-playing & $\begin{array}{l}\text { Activities aimed at letting a participant practice the use of techniques, } \\
\text { skills and solutions within a controlled and supervised setting. Often } \\
\text { focused around social situations. }\end{array}$ & 0.86 \\
\hline $\begin{array}{l}\text { Mapping social } \\
\text { opportunities }\end{array}$ & $\begin{array}{l}\text { Discussions or activities used to map potential opportunities for meeting } \\
\text { other people and expanding the social network. }\end{array}$ & 0.71 \\
\hline Goal-setting & $\begin{array}{l}\text { Discussions or activities centred around how to set personal goals and } \\
\text { evaluate progress towards them. }\end{array}$ & 0.63 \\
\hline $\begin{array}{l}\text { Stress } \\
\text { management }\end{array}$ & $\begin{array}{l}\text { Techniques, discussions, or exercises designed to help provide solutions to } \\
\text { problems causing unmanageable stress and make future occurrences of the } \\
\text { similar stressors more manageable. }\end{array}$ & 1 \\
\hline $\begin{array}{l}\text { Identifying } \\
\text { personal strengths }\end{array}$ & $\begin{array}{l}\text { Discussions or exercises designed to identify behaviours and traits with } \\
\text { which the participant have successfully managed to cope with demands in } \\
\text { the past. The intention is to help the participant identify their own } \\
\text { capability to handle current demands. }\end{array}$ & 1 \\
\hline $\begin{array}{l}\text { Emotional } \\
\text { awareness }\end{array}$ & $\begin{array}{l}\text { Discussions, information, or exercises designed to promote awareness of } \\
\text { emotions. }\end{array}$ & 0.66 \\
\hline Life-review & $\begin{array}{l}\text { Discussions or exercises that focuses on recalling events from one's past to } \\
\text { help enhance a sense of continuity of life events. }\end{array}$ & 1 \\
\hline $\begin{array}{l}\text { Reviewing } \\
\text { relationship } \\
\text { experiences }\end{array}$ & $\begin{array}{l}\text { Discussions or activities focused on reviewing past relationship } \\
\text { experiences and how these experiences can guide participants to enhanced } \\
\text { awareness and capability to handle current relationships. }\end{array}$ & 1 \\
\hline $\begin{array}{l}\text { Activity } \\
\text { scheduling }\end{array}$ & $\begin{array}{l}\text { The assignment or request that a participant identify or list activities the } \\
\text { participant finds pleasant or mood-elevating, and that the participant } \\
\text { schedule and participate in some of those activities, with the goal of } \\
\text { promoting or maintaining involvement in satisfying and enriching } \\
\text { experiences. }\end{array}$ & 1 \\
\hline
\end{tabular}


Running head: COMMON ELEMENTS APPROACH TO LONELINESS

Table 2. Study characteristics

\begin{tabular}{|c|c|c|c|c|c|c|}
\hline Study & $\begin{array}{l}\text { Participants } \\
\text { included }(n)\end{array}$ & $\begin{array}{l}\text { Mean age (age range } \\
\text { if reported) }\end{array}$ & $\%$ female & Description of sample & $\begin{array}{l}\text { Intervention } \\
\text { administered } \\
\text { in group? } \\
\text { Yes/No } \\
\end{array}$ & $\begin{array}{l}\text { Effect size for } \\
\text { treatment/control } \\
\text { comparison(s) } \\
(\text { Cohen's } d)^{*} \\
\end{array}$ \\
\hline Chiang et al., 2010 & 92 & $\begin{array}{l}77.4 \text { (treatment) / } 77 \\
\text { (control) }\end{array}$ & $0 \%$ & $\begin{array}{l}\text { Institutionalized elderly men over the } \\
\text { age of } 65 .\end{array}$ & Yes & 0.98 \\
\hline Creswell et al., 2012 & 40 & $65(55-85)$ & $83 \%$ & $\begin{array}{l}\text { Self-recruited older adults over the age } \\
\text { of } 55 \text {. }\end{array}$ & Yes & 0.91 \\
\hline Frankel et al., 2010 & 68 & $\begin{array}{l}8.6 \text { (treatment) / } 8.5 \\
\text { (control) }\end{array}$ & $15 \%$ & $\begin{array}{l}\text { Children with autism spectrum } \\
\text { disorders attending grade } 2 \text { through } 5 \text {. }\end{array}$ & Yes & 0.67 \\
\hline Matthews et al., 2018 & 34 & $\begin{array}{l}15.1 \text { (treatment } 1) / \\
15.2(\text { treatment } 2) / \\
15.4(\text { control })\end{array}$ & $18 \%$ & $\begin{array}{l}\text { Adolescents (age 13-17) with a } \\
\text { diagnosis within the autism spectrum } \\
\text { disorders-category. }\end{array}$ & Yes & $\begin{array}{l}1.08 \text { (Traditional } \\
\text { PEERS) } / 0.31 \\
\text { (PEERS with Peers) }\end{array}$ \\
\hline McWhirter \& Horan, 1996 & 44 & $24.8(18-38)$ & $48 \%$ & $\begin{array}{l}\text { Recruited from a university } \\
\text { counselling centre. Scored } 1 s d \text { above } \\
\text { the reported mean on a loneliness } \\
\text { measure. }\end{array}$ & Yes & $\begin{array}{l}0.86(\mathrm{UCLA}-\mathrm{I}) / 0.52 \\
\text { (UCLA-S) for the } \\
\text { social condition, } \\
1.17(\mathrm{UCLA}-\mathrm{I}) / 0.68 \\
\text { (UCLA-S) for the } \\
\text { combined } \\
\text { condition } \dagger\end{array}$ \\
\hline Theeke et al., 2016 & 27 & $75(65-79)$ & $89 \%$ & $\begin{array}{l}\text { Older adults with chronic illnesses } \\
\text { scoring over the mean level on the } \\
\text { loneliness measure. }\end{array}$ & Yes & 0.53 \\
\hline $\begin{array}{l}\text { Zhang, Fan, Huang, \& } \\
\text { Rodriguez, } 2018\end{array}$ & 50 & $\begin{array}{l}20.4 \text { (Treatment)/19.2 } \\
\text { (Control) }(17-25)\end{array}$ & $42 \%$ & $\begin{array}{l}\text { College students with elevated levels } \\
\text { of loneliness ( } 1 s d \text { over mean level). }\end{array}$ & Yes & 0.67 \\
\hline $\begin{array}{l}\text { Samarel, Tulman, \& Fawcett, } \\
2002\end{array}$ & 125 & 53.8 & $100 \%$ & Women with early-stage breast cancer. & $\begin{array}{l}\text { Yes, for one of } \\
\text { the conditions }\end{array}$ & $\begin{array}{l}0.52 \\
\text { (Combined)/0.65 } \\
\text { Telephone-only) }\end{array}$ \\
\hline Williams et al., 2004 & 801 & 20 & $27.5 \%$ & $\begin{array}{l}\text { Navy recruits in basic training } \\
\text { considered to be at-risk (elevated } \\
\text { symptoms of depression and perceived } \\
\text { stress). }\end{array}$ & Yes & $0.36 t$ \\
\hline
\end{tabular}


Table 2. (continued)

\begin{tabular}{|c|c|c|c|c|c|c|}
\hline Study & $\begin{array}{l}\text { Participants } \\
\text { included }(n)\end{array}$ & $\begin{array}{l}\text { Mean age (age range } \\
\text { if reported) }\end{array}$ & $\%$ female & Description of sample & $\begin{array}{l}\text { Intervention } \\
\text { administered } \\
\text { in group? } \\
\text { Yes/No } \\
\end{array}$ & $\begin{array}{l}\text { Effect size for } \\
\text { treatment/control } \\
\text { comparison(s) } \\
(\text { Cohen's } d)^{*} \\
\end{array}$ \\
\hline $\begin{array}{l}\text { Gantman, Kapp, Orenski, \& } \\
\text { Laugeson, } 2012\end{array}$ & 17 & $20.4(18-23)$ & $29 \%$ & $\begin{array}{l}\text { Young adults diagnosed with autism } \\
\text { spectrum disorders. }\end{array}$ & Yes & $1.13 \S$ \\
\hline Cohen-Mansfield et al., 2018 & 89 & $\begin{array}{l}76.6 \text { (Treatment)/79 } \\
\text { (Control) }(66-92)\end{array}$ & $81 \%$ & $\begin{array}{l}\text { Older adults (age } 65 \text { and over) } \\
\text { recruited from a multitude of sources. }\end{array}$ & $\begin{array}{l}\text { Yes, although } \\
\text { individual } \\
\text { sessions were } \\
\text { offered as well }\end{array}$ & 0.31 \\
\hline
\end{tabular}

* Not all studies used the same measure of loneliness. Effect sizes should be interpreted with caution.

$\dagger$ The study reported use of a multitude of loneliness measures. The calculated effect sizes represent two measures making up the UCLA Loneliness Scale, the most common measure used in the other studies.

$\$$ Estimated using the reported $t$-value and $d f$ s because of a lack of necessary reported means and standard deviations.

$\S$ Estimated using the reported $f$-value and sample sizes because of a lack of necessary reported means and standard deviations. 
Table 3. Practice elements found in respective study group

\begin{tabular}{|c|c|c|c|c|c|c|c|c|}
\hline Study & $\mathrm{C}$ & PS & MI & $\mathbf{E X}$ & $\mathbf{R E}$ & SCT & PE & $\mathbf{R P}$ \\
\hline \multicolumn{9}{|l|}{ Chiang et al., 2010} \\
\hline Creswell et al., 2012 & & & $\mathrm{x}$ & & & & & \\
\hline Frankel et al., 2010 & & & & & & $\mathrm{x}$ & & $\mathrm{X}$ \\
\hline $\begin{array}{l}\text { Matthews et al., 2018, Condition } 1 \\
\text { (Peer-mediated) }\end{array}$ & & & & & & $\mathrm{x}$ & & $\mathrm{X}$ \\
\hline $\begin{array}{l}\text { Matthews et al., 2018, Condition } 2 \\
\text { (Standard) }\end{array}$ & & & & & & $\mathrm{x}$ & & $\mathrm{X}$ \\
\hline $\begin{array}{l}\text { McWhirter \& Horan, 1996, } \\
\text { Condition } 2 \text { (Social) }\end{array}$ & $\mathrm{X}$ & & & & & $\mathrm{x}$ & $\mathrm{X}$ & $\mathrm{X}$ \\
\hline $\begin{array}{l}\text { McWhirter \& Horan, 1996, } \\
\text { Condition } 3 \text { (Combined) }\end{array}$ & $\mathrm{X}$ & & & & & $\mathrm{x}$ & $\mathrm{X}$ & $\mathrm{X}$ \\
\hline Theeke et al., 2016 & $\mathrm{X}$ & & & & & & $\mathrm{X}$ & \\
\hline $\begin{array}{l}\text { Zhang, Fan, Huang, \& Rodriguez, } \\
2018\end{array}$ & & & $\mathrm{x}$ & & & & $\mathrm{X}$ & \\
\hline $\begin{array}{l}\text { Samarel, Tulman, Fawcett, 2002, } \\
\text { Condition } 1 \text { (Group-delivered) }\end{array}$ & & $\mathrm{x}$ & & & $\mathrm{x}$ & $\mathrm{x}$ & $\mathrm{X}$ & \\
\hline $\begin{array}{l}\text { Samarel, Tulman, Fawcett, 2002, } \\
\text { Condition } 2 \text { (Phone-delivered) }\end{array}$ & & $\mathrm{X}$ & & & $\mathrm{X}$ & $\mathrm{x}$ & $\mathrm{X}$ & \\
\hline Williams et al., 2004 & $\mathrm{X}$ & & & & & & & \\
\hline $\begin{array}{l}\text { Gantman, Kapp, Orenski, \& } \\
\text { Laugeson, } 2012\end{array}$ & & & & & & $\mathrm{x}$ & & $\mathrm{X}$ \\
\hline Cohen-Mansfield et al., 2018 & & & & & & $\mathrm{x}$ & & $\mathrm{X}$ \\
\hline
\end{tabular}

Abbreviations. $\mathrm{C}=$ Cognitive, $\mathrm{PS}=$ Problem solving, $\mathrm{MI}=$ Mindfulness, $\mathrm{EX}=$ Exposure, $\mathrm{RE}=$ Relaxation, $\mathrm{SCT}=\mathrm{Social}$ skills and communication training, $\mathrm{PE}=$ Psychoeducation, $\mathrm{RP}=$ Role-playing. 
Table 3. (continued)

\begin{tabular}{|c|c|c|c|c|c|c|c|c|}
\hline Study & $\mathbf{S M}$ & IPS & $\mathbf{E A}$ & $\mathbf{A S}$ & LR & RRE & MSO & GS \\
\hline Chiang et al., 2010 & & $\mathrm{X}$ & $\mathrm{X}$ & & $\mathrm{X}$ & $\mathrm{X}$ & & $\mathrm{X}$ \\
\hline Creswell et al., 2012 & & & $X$ & & & & & \\
\hline Frankel et al., 2010 & & & & & & & $\mathrm{X}$ & \\
\hline $\begin{array}{l}\text { Matthews et al., 2018, Condition } 1 \\
\text { (Peer-mediated) }\end{array}$ & & & & & & & $\mathrm{X}$ & \\
\hline $\begin{array}{l}\text { Matthews et al., 2018, Condition } 2 \\
\text { (Standard) }\end{array}$ & & & & & & & $\mathrm{X}$ & \\
\hline $\begin{array}{l}\text { McWhirter \& Horan, 1996, } \\
\text { Condition } 2 \text { (Social) }\end{array}$ & $\mathrm{X}$ & & & & & & $\mathrm{X}$ & \\
\hline $\begin{array}{l}\text { McWhirter \& Horan, 1996, } \\
\text { Condition } 3 \text { (Combined) }\end{array}$ & $\mathrm{X}$ & & & & & & $\mathrm{X}$ & \\
\hline Theeke et al., 2016 & & & & & & $\mathrm{X}$ & & \\
\hline $\begin{array}{l}\text { Zhang, Fan, Huang, \& Rodriguez, } \\
2018\end{array}$ & & & $\mathrm{X}$ & & & & & \\
\hline $\begin{array}{l}\text { Samarel, Tulman, Fawcett, 2002, } \\
\text { Condition } 1 \text { (Group-delivered) }\end{array}$ & $\mathrm{X}$ & & $\mathrm{X}$ & & & & & \\
\hline $\begin{array}{l}\text { Samarel, Tulman, Fawcett, 2002, } \\
\text { Condition } 2 \text { (Phone-delivered) }\end{array}$ & $\mathrm{X}$ & & $\mathrm{X}$ & & & & & \\
\hline Williams et al., 2004 & $\mathrm{X}$ & & & & & & & \\
\hline $\begin{array}{l}\text { Gantman, Kapp, Orenski, \& } \\
\text { Laugeson, } 2012\end{array}$ & & & & & & & $\mathrm{X}$ & \\
\hline Cohen-Mansfield et al., 2018 & & & & & & & $\mathrm{X}$ & \\
\hline
\end{tabular}

Abbreviations. SM = Stress management, IPS = Identifying personal strengths, EA = Emotional awareness, AS = Activity scheduling, LR = Lifereview, $\mathrm{RRE}=$ Reviewing relationship experiences, $\mathrm{MSO}=$ Mapping social opportunities, GS = Goal-setting. 
Table 4. Explanation of the cognitive behavioural model of chronic loneliness and its relationship with other models

\begin{tabular}{lll}
\hline Component & Description & Rationale for inclusion \\
\hline Interpersonal trigger/context & $\begin{array}{l}\text { Loneliness is thought to rely on } \\
\text { contextual triggers. This could be } \\
\text { a major disruption of the social } \\
\text { network, such as in the case of } \\
\text { bereavement, or a temporary } \\
\text { occurrence, such as an update on }\end{array}$ & $\begin{array}{l}\text { DMM procedures: Mapping } \\
\text { relationship experiences }\end{array}$ \\
& $\begin{array}{l}\text { Literature on loneliness e.g. } \\
\text { Qualter et al., (2015) }\end{array}$
\end{tabular}

social media.

Values relationships
A prerequisite to the emergence of state loneliness is that the individual values relationships and places some worth in them in a given situation. This factor moderates the link between the interpersonal context and the state of loneliness and helps explain the fact that some individuals are perfectly content with their situation even with the objective absence of social contact.

\section{Notes}

The proposed model is compatible with the Reaffiliation Motive account (Qualter et al., 2015) which describes chronic forms of loneliness as the product of a dysfunction within the perceptual and cognitive aspects of this "system". The starting point of the process is the perception of being socially isolated. While this prompts reconnection, for a subgroup of the population it also increases the cognitive perception of threat and the behavioral tendencies to withdraw from social interaction.
Literature on loneliness e.g.

Long, Seburn, Averill, and More (2003) 
Table 4. (continued)

\begin{tabular}{ll} 
Component & Description \\
\hline Perceived mismatch between & The experience of loneliness is
\end{tabular}

actual and desired social situation the result of an appraisal of the

('loneliness')

Negative interpersonal appraisals Negative interpersonal appraisals are proposed to give rise to, and potentiate, cognitions related to the social domain that have been noted in the literature, often related to rejection e.g., People won't like me; I can't trust people.

\section{Rationale for inclusion}

DMM procedure: Mindfulness to address state loneliness

Literature on loneliness e.g., Peplau \& Perlman (1982)

DMM procedure: Cognitive, reviewing relationship experiences, psychoeducation, life review, identifying personal strengths

Literature on loneliness: e.g., Cacioppo \& Hawkley, 2009; Masi et al., 2011; Qualter et al., 2015; Young, 1982

Broader cognitive-behavioural literature e.g., Clark \& Wells, 1995

Emotional response (e.g., anxiety, The emotional response arising depression) from negative appraisals will vary and may be anxiety, low mood or feelings such as 'emptiness'.
DMM procedure: Relaxation, stress management, problemsolving, emotional awareness. Literature on loneliness (e.g., Cacioppo et al., 2015; Leary, 1990; Lim et al., 2016)

Broader cognitive-behavioural literature (e.g., Beck, 1979)

\section{Notes}

The triggering interpersonal context may be both the presence and absence of a desired social interaction.

Processes relating to 'social cognition' and 'cognition' and lack of positive responding to social inclusion can be considered here; strengths-based approaches and factors such as self-efficacy (Cohen-Mansfield \& ParpuraGill, 2007) may act to mitigate against the occurrence and impact of such appraisals.

Work on emotion regulation in loneliness is also relevant to addressing the emotional response and chronic loneliness appears to be associated with maladaptive emotion regulation strategies (e.g., Vanhalst, Luyckx, van Petegem, \& Soenens, 2018).

The emotional response is likely to be amplified in people with mental health disorders. 
Table 4. (continued)

\begin{tabular}{|c|c|c|c|}
\hline Component & Description & Rationale for inclusion & Notes \\
\hline $\begin{array}{l}\text { Counter-productive behaviour } \\
\text { (e.g. avoidance) }\end{array}$ & $\begin{array}{l}\text { Counter-productive behaviour are } \\
\text { behaviours that are reinforcing in } \\
\text { the short term but can become } \\
\text { problematic over time e.g., } \\
\text { avoidance, and withdrawal from } \\
\text { social interaction. }\end{array}$ & $\begin{array}{l}\text { Literature on loneliness: E.g., } \\
\text { Nurmi, Toivonen, Salmela-Aro, } \\
\text { and Eronen (1997) } \\
\text { Broader cognitive behavioural } \\
\text { literature on avoidance as } \\
\text { maintaining psychopathology and } \\
\text { counter-productive 'safety } \\
\text { behaviour' e.g. see Meulders, } \\
\text { Van Daele, Volders \& Vlaey, } \\
\text { (2016); Treanor \& Barry (2017) }\end{array}$ & $\begin{array}{l}\text { Exposure and activity scheduling } \\
\text { may be helpful and should be } \\
\text { included in cognitive behavioural } \\
\text { treatments of loneliness. }\end{array}$ \\
\hline Social-cognitive processes & $\begin{array}{l}\text { When entering social encounters, } \\
\text { lonely individuals may place an } \\
\text { unhelpful amount of attention on } \\
\text { themselves and their own } \\
\text { reactions rather than on the other } \\
\text { party. Individuals at risk for } \\
\text { chronic loneliness have also been } \\
\text { suggested to exhibit biases related } \\
\text { to information processing, such } \\
\text { as selective memory recall. These }\end{array}$ & $\begin{array}{l}\text { Literature on loneliness e.g., } \\
\text { Jones, Hobbs \& Hockenbury } \\
\text { (1982); Cacioppo \& Hawkley, } \\
\text { 2009; Spithoven, Bijttebier \& } \\
\text { Goossens (2017) } \\
\text { Broader cognitive behavioural } \\
\text { literature e.g., Mörtberg, Hoffart, } \\
\text { Boecking \& Clark (2015) }\end{array}$ & $\begin{array}{l}\text { Sensitivity to rejection (e.g., } \\
\text { Watson \& Nesdale, 2012) and } \\
\text { processes identified by Cacioppo } \\
\& \text { Hawkley, } 2009 \text { (i.e., } \\
\text { hypervigilance to social threat, } \\
\text { attentional and confirmatory and } \\
\text { memory biases) are included } \\
\text { within this factor and have been } \\
\text { proposed to be important } \\
\text { mechanisms of maintenance. }\end{array}$ \\
\hline
\end{tabular}
processes are active during and after the social situation. 
Table 4. (continued)

\begin{tabular}{|c|c|c|c|}
\hline Component & Description & Rationale for inclusion & Notes \\
\hline $\begin{array}{l}\text { Personal challenges such as social } \\
\text { skills deficits, mobility issues }\end{array}$ & $\begin{array}{l}\text { Lacking social skills is thought to } \\
\text { be reciprocally related to a } \\
\text { decrease in valued social } \\
\text { contacts. For some individuals, } \\
\text { such as those with ASD and } \\
\text { recognised social skills deficits, } \\
\text { this will be the primary factor } \\
\text { leading to a decrease of valued } \\
\text { social contact and chronic } \\
\text { loneliness. For others, } \\
\text { particularly older adults, mobility } \\
\text { and health issues may lead to a } \\
\text { decrease in valued social } \\
\text { contacts. }\end{array}$ & $\begin{array}{l}\text { DMM Procedure: Social skills } \\
\text { and communication training, role- } \\
\text { playing, mapping social } \\
\text { opportunities } \\
\text { Literature on loneliness e.g., } \\
\text { Cohen-Mansfield \& Parpura-Gill } \\
\text { (2007) and Qualter et al. (2015) } \\
\text { suggesting a decrease in social } \\
\text { opportunities leads to a reduction } \\
\text { of opportunities to strengthen } \\
\text { one's ability to manage social } \\
\text { situations }\end{array}$ & $\begin{array}{l}\text { Mobility and health issues are of } \\
\text { particular relevance to older } \\
\text { adults. People with pre-existing } \\
\text { mental health difficulties would } \\
\text { also be considered here. }\end{array}$ \\
\hline
\end{tabular}

